\title{
Algunas reformas institucionales pendientes
}

\author{
Some pending institutional reforms \\ JOSÉ RUBIO-CARRACEDO \\ Universidad de Málaga.
}

Recibido: 04-06-2007 Aprobado definitivamente: 21-09-2007

\section{RESUMEN}

El modelo democrático vigente, en especial el latino, adolece de un grave defecto de diseño: la excesiva hegemonía de los partidos políticos, sin cuya mediación -y mediatización-no es posible participar en la vida política. El autor traza la genealogía histórica del modelo partidocrático, con especial atención al caso español, y apunta las principales reformas constitucionales y legislativas que considera imprescindibles para conseguir una regeneración del modelo democrático.

\section{PALABRAS CLAVE}

PARTIDOCRACIA, REFORMA CONSTITUCIONAL, REVISION LEGISLATIVA

\begin{abstract}
The essay reviews the current-day implications of the democratic model. It argues that this model, particularly the Latin one, is subjected to important design failures, particularly the immoderate hegemony of political parties. Secondly, the author sketches the historical evolution of that model, with particular attention to the Spanish case, and shows the main constitutional and legal amendments that he estimates necessary in orden to attain the regeneration of the democratic pattern.
\end{abstract}

\section{KEY WORDS}

POLITICAL PARTIES, CONSTITUTIONAL AMENDMENTS, LEGAL REFORMS, SPANISH DEMOCRATIC MODEL 
RESULTA INDUDABLE QUE EN LOS ÚLTIMOS TIEMPOS crece más y más entre nosotros el descontento con la democracia, y no sólo por los continuos escándalos de corrupción urbanística. No sólo son muy pocos dirigentes políticos, del gobierno o de la oposición, los que consiguen el aprobado en las encuestas, sino que la clase política -los partidos- reciben desde hace muchos años la peor nota de valoración de todos los estamentos y profesiones. Y, no obstante, apenas se dibujan mínimas reformas del sistema, en lugar de asumir la revisión en profundidad de nuestro modelo democrático en tanto que democracia deficitaria.

Habría que comenzar, al menos, por los puntos más sangrantes y que tienen, además, una función estratégica. El más reconocido es, sin duda, la reforma urgente de la Ley Electoral. Pero, de modo simultáneo, habría que reformar la Ley de partidos políticos, ya que ambas leyes constituyen el armazón de nuestra partidocracia, responsable de casi todas las desviaciones y defectos de nuestro modelo democrático. Defectos que, en ocasiones, apenas son percibidos por la opinión pública, pero cuyo origen se encuentra ya en la Constitución de 1978 como efecto del modelo partidista entonces adoptado. Baste citar como casos más notorios el diseño de los referendos consultivo y de reforma de la Constitución, el de la iniciativa legislativa popular y la desnaturalización del Senado. Pero el sesgo partidocrático se observa, sobre todo, en las leyes orgánicas que desarrollan los preceptos constitucionales, que también claman, en su casi totalidad, por una revisión general de aquel modelo.

En este trabajo me propongo señalar solamente algunos casos notorios que desvirtúan gravemente el carácter de «democracia avanzada» que de modo más bien voluntarista proclama nuestra Constitución en su Preámbulo. Pero llegaré a señalar, incluso, algunas desviaciones normativas que afectan a la propia Constitución y que exigen su reforma. Tales son los artículos antes mencionados, relativos al referéndum consultivo y a la iniciativa legislativa popular, además de lo referente al Senado. Aunque nos encontraremos con la paradoja de que el diseño del referéndum de reforma de la Constitución blinda ésta de tal manera que hace casi impracticable cualquier reforma de importancia. Una vez más por efecto del sesgo partidocrático general.

Como es sabido, en ocasiones, los mismos partidos políticos toman acuerdos para la reforma de tal o cual ley orgánica. Pero, o lo hacen en términos genéricos, que no conducen a ninguna reforma digna de mención (como ha ocurrido con la Ley electoral), o lo hacen en forma de coaliciones que presentan enmiendas interesadas, o con correcciones singulares de un oportunismo manifiesto. En cualquier caso, sus enmiendas nunca buscarán atemperar la partidocracia, sino más bien blindarla todavía más, ya que, aunque discrepen en todo lo demás, la partidocracia es el dogma en el que todos comulgan. 
Por eso, antes de hablar de reformas concretas, se hace necesario echar una mirada histórico-reflexiva a los orígenes y la consolidación del fenómeno partidocrático y su contaminación de la democracia. Obviamente, me refiero a las desviaciones partidistas, no a la existencia de los partidos políticos que, incluso en Suiza, forman parte esencial de las instituciones democráticas. Del mismo modo que el grado de desviación partidista es muy diferente en unos modelos liberales de representación que en otros. Cabe reseñar en este punto que tuvo una importancia decisiva que los coautores de nuestra Constitución se fijasen casi en exclusiva en el modelo latino (Italia, Francia y parcialmente Alemania), en lugar de inspirarse también en los modelos nórdico y anglosajón.

\section{EL COTO VEDADO DE LA DEMOCRACIA REPRESENTATIVA INDIRECTA}

No se puede perder de vista que el actual modelo de representación democrática indirecta tuvo su origen en los enconados debates constitucionales entre liberales y republicanos que siguieron a las Revoluciones Americana y Francesa. No puedo detenerme aquí en su detalle y me remito a trabajos previos y especialmente a B. Manin (1998). Los historiadores de las ideas políticas siguen presentando las Revoluciones Liberales vestidas de blanco (frente al Antiguo Régimen opresivo y arbitrario), y suelen desestimar, además, el papel de fermento indispensable que jugaron las ideas republicanas. Sobre esta base no resulta extraño que los liberales aparezcan como progresistas y las ideas republicanas como anticuadas. Es cierto que la gran tradición republicana no había actualizado su modelo democrático, pero sin la misma resultan ininteligibles tanto Locke como Montesquieu, para no hablar ya de Rousseau. Es indudable que el modelo republicano tenía un sesgo excesivamente comunitarista. Pero lo procedente hubiera sido trabajar conjuntamente tanto en la depuración como en la actualización de la tradición democrática republicana. En el debate se optó, sin embargo, por la eliminación del republicanismo como un estorbo para las ideas liberales, sobre todo en Francia (y Europa), porque los liberales percibían el republicanismo (es cierto, los excesos jacobinos pesaron demasiado) no como un posible socio y aliado, sino como un enemigo.

¿Por qué fue así? Para comprenderlo es preciso profundizar más en el sentido de la revolución liberal. Se trataba, desde luego, de abolir el Antiguo Régimen y conquistar la libertad individual, junto con los demás derechos civiles y políticos. Pero se trataba también de liberar al individuo de todas las interferencias, estatales, nacionales y de los demás individuos. La conquista real fue la del individualismo. Nada extraño si tenemos en cuenta que fue la burguesía comercial e industrial la gran fuerza revolucionaria. Sin llegar a calificarlo de «individualismo posesivo» (Macpherson), resulta claro que el liberalismo estaba 
interesado primordialmente en la libertad de toda interferencia, esto es, en la primacía de la iniciativa privada incondicionada. De ahí que la democracia republicana, con sus vínculos cívicos y políticos, no despertara precisamente sus simpatías. Una frase del abate Sièyes resulta bien significativa al respecto: «el concurso inmediato es lo que caracteriza a la verdadera democracia. El concurso mediato designa al gobierno representativo. La diferencia entre estos dos sistemas políticos es enorme».

La participación política de los ciudadanos inspiraba una innegable repugnancia a un buen número de liberales, al sentirla más como una obligación que como un derecho. En efecto, el liberalismo conservador -que fue el que se impuso con Burke o Constant- se complacía en la libertad negativa-libertad de todo tipo de interferencias, aunque también de todo tipo de dominación, pese a Pettit (1999) - y en los derechos civiles. Claro está que existe otra corriente liberal «evolutiva» (Held 1996) o afirmativa (Rubio Carracedo 2005), que incide fuertemente en los derechos políticos. Pero, pese al prestigio de un Tocqueville o un J. S. Mill, no logró imponerse en la práctica. Ello hizo posible que triunfase ampliamente, sobre todo en la Europa Latina, un modelo de representación indirecta que no sólo enturbia la democracia sino que resulta incompatible con el espíritu mismo del liberalismo que proclama que el individuo es el único intérprete autorizado de sus intereses.

Contra lo que en ocasiones se afirma, nunca se adujo como razón básica para adoptar tal sistema la impracticabilidad del republicanismo o de otros modelos más participativos. Porque la lógica liberal exigía como mínimo un modelo de representación directa, como la vengo denominando (2005). Este modelo de representación directa incluye al menos cuatro exigencias básicas: a) listas abiertas de candidatos a representantes políticos; b) un programa político real vinculante, y no sólo propagandístico, para solucionar los problemas de los ciudadanos, diseñado deliberativamente; c) rendición de cuentas continuada a la opinión pública; y d) revocabilidad política del representante que ha perdido la confianza de sus electores.

¿Por qué se impuso, en cambio, el modelo de representación indirecta (con listas cerradas y bloqueadas, programa propagandístico, con rendición de cuentas solamente genérica y final, sin exigencia de revocabilidad)? Porque, como antes dejé indicado, los individuos liberales ansiaban la plena dedicación a sus iniciativas empresariales de todo tipo. Lo que, a su vez, indujo la concepción de la política como una empresa. De ahí que de inmediato surgiese una clase profesional dedicada a la política, que la declaró su «coto vedado», que tampoco estaba dispuesta a tolerar interferencias de los ciudadanos, para lo que el modelo de representación indirecta resultaba ideal. Pocos años después, B. Contant declarará con gran énfasis que, a diferencia de los Antiguos, que centraban su libertad en la participación política, los Modernos la cifraban en la libertad 
privada. Por eso añadió con igual éxito que la representación política había sido la gran conquista de la Revolución, pese a que reconocía que con ella «sólo se ejerce la soberanía por representación, esto es, de manera ficticia» (1818).

¿Cómo fue posible, pese a todo, una falacia tan flagrante como la representación indirecta? Mediante el concurso de otras falacias e inflexiones semánticas. Como ha demostrado Torres del Moral, Sièyes y Condorcet tuvieron un papel destacado en la gestación de esta falacia de la representación indirecta. Su influencia indudable en el texto constitucional de 1791 se hace notar en la prohibición del mandato imperativo y de la revocación de los diputados. Su evolución hacia la defensa de una independencia total del representante respecto del representado llega hasta considerar que la represención tiene la primacía sobre el ser elegido, basándose en el caso británico de la Cámara de los Lores. En definitiva, se es representante porque se pertenece al cuerpo legislativo (¿Qué es el tercer estado?, cap. V).

Obviamente, el liberalismo doctrinario acogerá con gozo esta bandera de la autonomía completa del cuerpo representante. ¿Por qué se mantiene entonces el voto popular? Porque era significativo a efectos de legitimación. Pero lo importante era representar a la nación; el ser elegido tenía sólo un sentido instrumental. Se ha producido, pues, una primera inflexión semántica: la de Pueblo a Nación. Todavía en la primera constitución de 1791 el término nación aparece pocas veces como sínónima de pueblo, pero siempre con mayúscula; en la constitución jacobina de 1793 (que fue aprobada pero no llegó a entrar en vigor) está casi totalmente ausente el término nación; pero en la definitiva de 1795 el término Nación remplaza totalmente a pueblo, que sólo sirve para evitar reiteraciones de Nación. La inflexión semántica ha tomado, pues, cuerpo constitucional.

Pero se da una segunda inflexión semántica que viene a reforzar la primera: la que permite pasar de «representación» a «representación democrática» y finalmente a «democracia representativa». Cordorcet fue su principal valedor. Ya en un opúsculo de 1788 avanzaba que el sistema de representación -propio de los grandes estados, mientras que la democracia lo era de los pequeños-era igualmente democrático, porque expresaba también la voluntad de los ciudadanos. En 1790 acuña los términos «democracia inmediata» y «democracia representativa» (Torres del Moral 1975, pp. 190-1). Esta segunda inflexión encontró más resistencias (Constant, Tocqueville). En su Inédit sur la Revolution, Tocqueville parece escandalizarse de tal abuso del término «democrático», pero acaba por reconocer que sirve a efectos legitimadores, ya que «ilusiona a la masa popular».

Parece innegable, pues, la inconsistencia del modelo de representación indirecta con el espíritu y la letra del liberalismo, a diferencia de la representación directa. ¿Por qué terminó, sin embargo, imponiéndose? Sin duda por razones 
pragmáticas. No hay que echar en olvido la atmósfera ilustrada («todo para el pueblo, pero sin el pueblo») en que se desarrollaron los debates posrevolucionarios. Uno de los tópicos más comunes era el de «la tiranía de las mayorías». El componente elitista resulta esencial porque otro lugar común era que el pueblo es y será siempre ignorante y voluntarista. Y eso que hablamos del voto censitario, esto es, de que las elecciones eran asunto de los censados (es decir, de los propietarios y autónomos que pagaban al fisco). Pero es que, además, ¿quién podía presentarse con garantías como candidato a las elecciones? Unicamente quien tuviera medios de fortuna y relaciones sociales. Esto es, básicamente la nobleza aburguesada o la burguesía comercial e industrial. Por tanto, el sistema de representación indirecta favorecía la formación de una clase política profesional, «un coto vedado» que propiciaba que las desigualdades sociales en el ámbito privado se trasladasen también a la esfera pública.

Obviamente, han pasado casi dos siglos de esta genealogía de la representación indirecta. Algunos autores han planteado que se trató de un primer paso, el único que podía darse, entre el régimen despótico y la plena democracia. En esta línea puede situarse la posición de Bobbio (1985) cuando afirma que, pese a la inevitable disparidad entre la teoría y la práctica, siempre habían existido unas «promesas» nunca realizadas, que resume en estas seis: a) la supresión de los cuerpos intermedios; b) la salvaguarda de los intereses nacionales; c) la eliminación de las oligarquías; d) la supresión de los poderes invisibles; e) la participación más amplia posible de los ciudadnos en las decisiones colectivas; y f) la educación del ciudadano. Pero Bobbio termina por aceptar que fueron promesas incumplidas porque la creciente complejidad social y la consiguiente necesidad de técnicos y burócratas impidió una profundización de la democracia, dado que, además, ello hubiera «sobrecargado» el sistema abocándole a la «ingobernabilidad». Del mismo modo explica la creciente hegemonía del ejecutivo sobre el legislativo y el judicial. Y es que, pese a sus «deficiencias y desviaciones», la democracia «formal» es «el único sistema democrático posible» (ib., pp. 25-45). Las exigencias de una mayor participación política podría conducirnos a la «computericracia» y a lo que Dahrendorf ha llamado «el ciudadano total», que opina de todo y decide sobre todo (ib., pp. 51-80).

La posición de Bobbio es compartida por muchos autores de la constelación liberal. Pero en los últimos veinticinco años ha repuntado con fuerza la inspiración republicana. Baste citar los casos de Barber, Habermas, Pettit... Personalmente prefiero más bien una cierta síntesis de liberalismo afirmativo y de republicanismo moderado, que recoge las mejores aportaciones del liberalismo (derechos civiles, derecho a la privacidad, representación política directa) y de la democracia republicana (derechos políticos plenos, sentido de la comunidad política, ciudadanía activa y vigilante) que he caracterizado como democracia de «representación directa», antes aludida (Rubio Carracedo 2000, 2005). 
Porque parece incuestionable que las razones invocadas para disculpar la no realización de las promesas liberales resultan poco convincentes y en algún caso hasta paradójicas. ¿Por qué la creciente complejidad social desaconsejó la eliminación de las oligarquías y la supresión de los poderes invisibles, junto con la salvaguarda de los intereses nacionales sobre los individuales? Concedamos que no aconsejó la supresión de los cuerpos intermedios y la participación máxima directa de la ciudadanía en las decisiones colectivas, pero ¿por qué no acometer la educación del ciudadano y el desarrollo de la cultura cívica frente a las nuevas y complejas realidades?

El último interrogante me parece especialmente significativo. Fuera de algunos autores como Tocqueville y J. S. Mill (liberalismo afirmativo), la preocupación por la educación ciudadana es prácticamente nula en el liberalismo conservador. Lo único que importa de los ciudadanos es el voto electoral clientelar y legitimador. Podría suponerse que, tras la irrupción de los partidos políticos en la escena política en la segunda mitad del siglo XIX y la progresiva universalización del voto electoral, era lógico que se hubiera despertado una mayor sensibilidad para promover la cultura cívico-democrática. Pero no fue así. Y es que los nuevos partidos, pese a sus diferentes ideologías e intereses, se acomodaron de inmediato a la democracia formal. Es decir, a la partidocracia. Tanto que primeramente Ostrogorski la denunció como nueva forma de oligarquía y poco después Michels (1911) pudo formular su «ley de hierro de la oligarquización» de los partidos políticos.

Resulta significativo que Weber apenas matizara las tesis de Michels y que más recientemente sólo Dahl haya intentado reconvertirlas en su poliarquía: se trata de una tendencia estructural hacia la oligarquización, pero un equilibrio bien diseñado entre los vectores básicos de «autonomía vs. control» resuelve el problema (Dahl, 1982). Es más, considero que la propuesta poliárquica de Dahl, con partidos competitivos luchando por sus objetivos, pero en condiciones siempre de igualdad y de lealtad entre sí, constituye un ideal permanente e indispensable de toda democracia. Pero los autores de inspiración liberal suelen pasar de puntillas sobre este problema, con alguna excepción como la de Manin (1998). Mucho más problemática me parece la estructura de los «partidos-cartel», que huyen de la colisión para reconciliar intereses en la colusión. Tanto que, en realidad, siempre están parcialmente en el gobierno. Con ello se pretende evitar las asperezas de la competencia y asegurar la estabilidad política a base de negociación, lo que indudablemente favorece el conservadurismo, como ilustra bien el ejemplo de la democracia helvética, aunque sea casi ejemplar en aspectos como la iniciativa popular y el referéndum. 


\section{El SESGO PARTIDOCRÁtICO DE LA CONSTITUCIÓN}

Hasta cierto punto, resultó inevitable que los autores de la Constitución de 1978 reforzaran al máximo el papel de los partidos políticos, tras su larga persecución por el régimen franquista. Ellos mismos eran miembros de partidos y se aferraron a la fórmula: democracia = partidos. E, igualmente, que se fijaran en el modelo que les era más familiar por sus relaciones de partido: Italia, Francia y, en menor medida, Alemania; es decir, básicamente el modelo latino de partidocracia.. De hecho, la ley de partidos políticos es preconstitucional y continúa todavía vigente. Parece innegable que dejó su sesgo en la Constitución. No obstante, puede decirse que el proyecto constitucional original -el Libro Blanco- fue sometido en el Congreso a una mayor deriva partidocrática (en especial por lo que toca al referéndum y a la iniciativa legislativa popular). De todos modos, la posición de los partidos políticos como tales en la Constitución es hegemónica, pero no tan abusiva como las leyes orgánicas que desarrollaron el articulado. En efecto, el art. 6 dice: «Los partidos políticos expresan el pluralismo político, concurren a la formación y manifestación de la voluntad popular y son instrumento fundamental para la participación política. Su creación y el ejercicio de su actividad son libres dentro del respeto a la Constitución y a la Ley. Su estructura interna y su funcionamiento deberán ser democráticos».

El problema está en que los partidos lo han entendido siempre como si dijera: los partidos políticos «monopolizan» el pluralismo político, «copan» la formación /.../ y son «el instrumento único para la participación política», dejando, además, en sordina la exigencia nítida de tener una estructura y un funcionamiento democráticos en favor de prácticas claramente oligárquicas y hasta monocráticas (el líder del partido: González, Anguita, Aznar...). La organización partidocrática de la democracia se expresa directamente en la ley electoral (con sus listas cerradas y bloqueadas), el bochornoso diseño de los tipos de referéndum y la limitación abusiva de la iniciativa legislativa popular, aparte de un sinnúmero de leyes que blindan definitivamente una hegemonía a todas luces desmesurada. Sin partido no es posible participar en la política. Incluso la práctica de fichar personas independientes de prestigio ha llegado progresivamente a cero ante las protestas de las bases: la política pertenece a la clase profesional de los partidos políticos, que se postulan como vivero único de todo y para todo cargo público. «Si no sabemos, ya aprenderemos», como dijo el diputado perpetuo.

\section{LAS CONSECUENCIAS DE LA PARTIDOCRACIA}

La consecuencia general es que nuestro modelo de democracia está penetrado por un espíritu mucho más oligárquico que realmente democrático. De 
ahí que en la praxis política se adopten con toda espontaneidad las reglas del naturalismo político (eufemísticamente denominado «realismo» político). En efecto, es muy frecuente que se utilice la expresión «en política hay que...» como equivalente a «en democracia hay que...». Basta con llamar la atención sobre el abuso para que, en efecto, se haga manifiesta la diferencia. El objetivo único y recurrente de la partidocracia es la obtención y el mantenimiento del poder; el servicio público tiene sólo una función instrumental. Y ello es así no sólo en campaña electoral -virtualmente siempre presente, por lo demás-, sino en el programa mismo de gobierno: se promete o se hace lo que proporciona votos o, al menos, se evita sistemáticamente lo que puede tener efectos electorales adversos. El poder es el único fin en sí mismo y no existe código ético democrático que lo regule: excepto la violencia física todo vale, todo está permitido, por más desleal e injusto que resulte. «Es el poder, estúpido», porque con el poder viene todo lo demás: prestigio social, riqueza, fama, influencias... Los impresentables, en cambio, son los otros... Lo que trae consigo algunas consecuencia graves:

a) Los ciudadanos como meros clientes electorales. Esta condición es particularmente clara durante las campañas electorales, enfocadas desde la mera propaganda, pero alcanza a la totalidad de la vida política. La propaganda, sumamente costosa al erario público, por cierto, se centra en vender a los electores unas listas electorales y un programa lleno de promesas destinadas a ganar votos, sin sentirse realmente vinculados por las mismas.

b) Los ciudadanos como «forofos» de los partidos. Un efecto directo de la partidocracia es la permanente minoría de edad política de la ciudadanía y la adscripción de los ciudadanos a los partidos políticos, no como afiliados (apenas el 5\%), sino como «forofos» o «hinchas» de los equipos deportivos, con su ceguera característica (el 60\% del electorado vota siempre e indefectiblemente al mismo partido: «soy del partido X»). Y no dudan en votar a sus ídolos incluso cuando están imputados judicialmente. No vale aducir que todavía no se ha sustanciado la responsabilidad penal, porque la responsabilidad política descansa sobre la confianza ciudadana, que la imputación judicial socaba por completo. Obviamente, todavía quedan ciudadanos independientes y reflexivos, que meditan su voto en cada elección o deciden votar en blanco (entre el 15\% y el 20\%), quedando el resto en el fondo variopinto de la abstención.

c) Los gastos sin fondo de la financiación partidista provocan corrupciones de todo tipo. Es éste uno de los efectos más conocidos del sesgo partidocrático. El partido se comporta como una gran empresa, con sus empleados fijos, y precisa siempre de más y más financiación. La 
estatal, con ser considerable, no es suficiente para una voracidad siempre mayor. La corrupción urbanística resulta ya escandalosa, pero es solamente la forma más visible de esa madeja característica que es la corrupción, tanto para los partidos como para los cargos individuales. Y eso que, con seguridad, sólo aflora la punta del iceberg, dado que notables talentos asesoran para no dejar pistas. Y lo más curioso: los partidos acusan a la escasa financiación pública que reciben como la causa de la corrupción y, consiguientemente, solicitan y obtienen -por ellos mismos- un $20 \%$ más de financiación pública para 2008, mientras intentan regular la financiación privada de modo más aparente que real (Nueva ley de financiación de los partidos políticos, aprobada en 2007). La cleptocracia seguirá su rumbo, aunque cambie de formas, porque representa una necesidad del sistema partidocrático vigente. Y el caso es que la existencia del Tribunal de Cuentas debería hacerla imposible. Pero también sobre este Tribunal pende la partidocracia: carece de medios para investigar y de poder sancionador directo.

d) La politización de la justicia. Este es uno de los efectos más graves del sistema partidocrático, que no sólo induce la alineación de los ciudadanos, sino también la de los jueces y fiscales. La elección de los diferentes Tribunales sigue el modelo de cupo o capacidad de elegir el número de vocales que corresponda al porcentaje de representación electoral (vocales muy afines, claro está). Así el Tribunal Constitucional es nombrado por el Congreso y el Senado (4 miembros cada uno), a los que el Gobierno de turno añade 2 y el Poder Judicial otros 2 . Aunque en este caso no parece tan grave, ya que se trata de un tribunal más legislativo que judicial. Pero la situación es similar para los 21 miembros del Consejo General del Poder Judicial, con lo que se fuerza claramente el espíritu y la letra de la Constitución (art. 122), y para los 13 miembros del Tribunal Supremo, que quedan asignados implícitamente a los partidos desde la misma Constitución (art. 123). El torpe diseño de tomar las decisiones por $2 / 3$ para evitar los abusos de la simple mayoría absoluta no previó, en cambio, que tal exigencia podría llevar a la inoperancia, como demuestra la escandalosa situación del Tribunal Constitucional y la del CGPJ.

Junto a esta subordinación del poder judicial parece una causa menor que el Fiscal General sea nombrado y «dirigido» por el gobierno, a la vez que aquél dicte la política a seguir al cuerpo de fiscales, jerárquicamente sometidos. Como resultado final la justicia se «partidiza» y el sesgo partidista de ciertas sentencias por influencia de uno u otro grupo político resulta manifiesto. La realidad es que la separación de poderes en nuestro sistema democrático queda en entredicho con frecuencia; porque tampoco el legislativo es independiente del ejecutivo. 
e) La desnaturalización del parlamento. En lugar de ser la cámara institucional del debate político pluralista, el parlamento (Congreso y Senado) se ha convertido en instrumento propagandístico para exhibir todo un repertorio de malevolencia y deslealtad, cuando no ya de insultos y tergiversaciones graves. Por otra parte, es la simple cámara de las ceremonias, donde se vota lo ya previamente decidido en otros ámbitos privados. ¿Para qué pagamos tantos diputados y senadores? Se ha dicho, con razón, que sobraría con 50, y casi con los protavoces de los grupos parlamentarios, debatiendo y negociando como de costumbre, y decidiendo con el voto ponderado de la representación respectiva.

La ventaja de contar con un sistema de partidos competitivos frente a los sistemas de «partidos-cartel», se pierde por su exceso de partidismo desleal (sí, partidismo viene de partido y éste de parte). Consiguientemente, un gran volumen de la legislación aprobada es igualmente parcial, por lo que suele ser desenfocada y muy perecedera. De igual modo, las sesiones de control al Gobierno resultan caóticas y propagandísticas (pensando en la TV); lo cierto es que no controlan nada. Y ¿qué decir de las comisiones de investigación si ya ni siquiera se solicitan? Se da, igualmente, un abuso injustificado del decreto-ley amparándose en una pretendida urgencia, que suele ser puro electoralismo.

f) La banalización del voto electoral. Como antes dejé indicado, el sistema electoral en España sirve a los intereses de los partidos (en especial de los mayoritarios) y no al interés general. La condición del ciudadano-elector se ve rebajada a la de simple cliente o comparsa a quien se fuerza a elegir entre unas listas cerradas y bloqueadas, elaboradas y, por tanto, elegidas previamente por las cúpulas burocráticas de los partidos. La inclusión o no en tales listas, y el lugar que se ocupa en las mismas, condiciona íntegramente la actuación de los aspirantes. Consiguientemente la disciplina oligárquica se impone sobre el criterio personal, por irrenunciable que sea. Y los ciudadanos, a quienes se dice que su voto electoral es su garantía para controlar y regular finalmente el sistema democrático, se encuentran forzados a refrendar una elección partidista previa en una actitud de trágalas (lo tomas o lo dejas). Lo que no es problema para la mayoría de «forofos», pero sí para la minoría independiente que ha de optar entre varias salidas insatisfactorias: el voto útil, el voto de castigo, el voto en blanco, el voto nulo o la simple abstención. Lo que implica también la banalización de la democracia: el ciudadano acude a las urnas supuestamente como árbitro y se encuentra con que no puede votar a quien quiere elegir. ¿Cómo puede mantenerse ese vergonzoso bloqueo de las listas ya cerradas? 
g) La devaluación de la condición de diputado. De los puntos anteriores se sigue una injustificable devaluación de la condición del diputado. La partidocracia es, en definitiva, una oligarquía que divide a los diputados en tres categorías: los de primera (los que deliberan y deciden las consignas), los de segunda (a quienes ocasionalmente se recurre) y los de tercera («los gusanos votantes»), la gran mayoría que ha de atenerse a una disciplina férrea de voto y de palabra, en la que se juegan además su futuro, porque «quien se mueve no sale en la foto». ¿Por qué aceptan esta posición subalterna? Porque es un modus vivendi y, con mucha frecuencia, no tienen otra profesión o juzgan un fracaso retornar a ella. Mientras tanto, el interés general se esfumó de su mente y sólo resta el interés privado disfrazado de interés del partido $X$, aunque siguen insistiendo en que buscan el interés público. Quizá, pese a todo, si resultan cómodos para la oligarquía del partido consigan ser diputados perpetuos. O tal vez se presente alguna ocasión ventajosa de transfuguismo. Por lo demás, ¿a quién representan nuestros representantes, fuera de los «forofos» de turno?

\section{Algunas Reformas InSTItUCiOnALES URGENTES}

Se van a cumplir 30 años de la Constitución y de democracia partidocrática en España. Aunque sólo fuera por el paso del tiempo, es lógico que cada generación pueda remozar y aprobar su propia Constitución. Tanto más en nuestro caso cuando es obvio que se trató de un producto negociado en términos posibilistas, aunque mereció un aprobado alto. Pero son numerosos los artículos que piden ser revisados y reformulados. Aquí me limitaré a señalar solamente los cuatro ya avanzados: la reforma del Senado (art. 69), el referéndum consultivo (art. 92), el referéndum de reforma de la Constitución (arts. 166-9), y la regulación de la iniciativa legislativa popular (art. 87.3). Y, obviamente, con mayor razón se hace preciso reformar las respectivas leyes Orgánicas que los desarrollan. Y resulta todavía más urgente la reforma de muchas de las leyes orgánicas que desarrollan tendenciosamente otros tantos artículos constitucionales. No obstante, aquí me limitaré a las ya apuntadas.

\section{a) La transformación del Senado en la Cámara de las Autonomías.}

Probablemente es ésta una de las reformas constitucionales que concita mayores adhesiones. En efecto, el diseño actual del Senado como Segunda Cámara legislativa de segunda lectura lo condena a ser una institución secundaria y casi irrelevante, dado que en caso de discrepancia respecto del proyecto legislativo 
aprobado por el Congreso se impone el dictamen final de este último. En absoluto se justifica tanto dispendio del erario público para tan poco rendimiento democrático.

Lo cierto es que la Constitución comienza por definirlo como la Cámara de «la representación teritorial» (art. 69.1). Pero se abstiene de desarrollar tal estatuto territorial más allá que mediante la prescripción de cuatro senadores por provincia, a los que añade un senador más por Comunidad Autónoma y otro más por cada millón de habitantes de su respectivo territorio. Pero los senadores autonómicos no son elegidos por votación ciudadana, sino que son designados por los parlamentarios autonómicos según la representación proporcional, esto es, según la aritmética de los partidos políticos. Con este diseño, la única, y parcial, cámara territorial la constituyen los parlamentos autonómicos en ausencia de una verdadera Cámara en la que pudieran debatir conjuntamente sus iniciativas políticas en cuanto Comunidades Autónomas. Así, pues, tanto por la forma de elegir a los Senadores, como por su diseño constitucional como Segunda Cámara legislativa subordinada, parece innegable que su función de representación territorial resulta inexistente en la práctica.

Nada impediría, en cambio, transformarla en un verdadera Cámara Territorial o de las Autonomías. Existe, incluso, un modelo relativamente cercano: el modelo alemán del Bundesrat o Consejo Federal, cuyo diseño y funcionamiento es marcadamente territorial. Habría que tener en cuenta, obviamente, las diferencias entre el modelo federal alemán y el modelo autonómico español, eufemísticamente denominado por alguien como «federalismo asimétrico», aunque resulta obvio que se trata de un confederalismo sui generis. En todo caso, la asimetría permanecería más bien en las atribuciones respectivas de los Parlamentos Autonómicos, mientras que el Senado funcionaría básicamente como la cámara territorial en la que los senadores, en tanto que representantes de las distintas Autonomías, debatirían entre sí y tomarían conjuntamente iniciativas políticas y legislativas, al menos en cuanto control eficaz de la legislación emanada del Congreso, así como de las políticas gubernamentales. Ello traería, sin duda, nuevos problemas, pero el Senado recuperaría su papel de Cámara Territorial que la Constitución enuncia, pero no desarrolla apropiadamente.

\section{b) El referéndum plebiscitario y consultivo.}

Como ya quedó apuntado, el Anteproyecto constitucional era, en general, mucho más avanzado democráticamente de lo que resultó la Constitución tras su paso por el Parlamento. En el caso que nos ocupa, el Libro Blanco preveía, además del ordinario para las cuestiones políticas de especial trascendencia, los referendos de ratificación (para leyes parlamentariamente aprobadas, pero todavía no sancionadas, que suscitasen especial controversia) y de abrogación 
(para derogar leyes vigentes). Fue precisamente la izquierda (comunistas y socialistas) la responsable de suprimir los dos últimos y de darle talante plebiscitario y consultivo al primero (art. 92), con el pretexto de que el pueblo podría ser manejado por los poderes fácticos para impedir la legislación progresista del parlamento. Me parece un caso claro de formación reactiva: ¿en qué pueblo pensaba nuestra izquierda política? Se trataba, en realidad, de un blindaje más de la partidocracia, vetando la participación ciudadana hasta producir el oxímoron flagrante de «referéndum consultivo» y, además, plebiscitario, ya que es el presidente el único que puede tomar la iniciativa de convocarlo, con la simple aprobación del parlamento (aunque la ley orgánica respectiva añadía también, por su cuenta, la aprobación del Consejo de Ministros). Esto es, como un instrumento de legitimación y propaganda al arbitrio del poder. Por lo demás, en las tres únicas ocasiones en las que ha sido convocado, el gobierno ha tomada parte muy activa en la persuasión de los ciudadanos, en lugar de limitarse a ofrecer información, como en su día reclamó P. del Castillo (1978), con ocasión del mismo referéndum constitucional. Es decir, como en un plebiscito de la dictadura.

R. Soriano (2002, cap. X) ha vuelto a incidir fuertemente sobre esta cuestión, recogiendo además una selección de la literatura producida al respecto. Anecdóticamente, entre la misma se encuentra un artículo de J. L. Rodríguez Zapatero, cuando era profesor en la Universidad de León, quien lo denominaba «referéndum de orientación plebiscitaria». En cuanto al carácter vinculante baste citar las palabras de A. Torres del Moral: «cuando el pueblo habla... decide» (I, 1985) o la más irónica de J. de Esteban: no tomar en cuenta el resultado de un referéndum sería «un golpe de estado constitucional» (1982).

Suscribo, pues, la propuesta de enmienda de Soriano en lo que se refiere a suprimir el ridículo aditamento de «consultivo», a recuperar los referendos de ratificación y de derogación de las leyes, a dar la iniciativa de convocatoria al Congreso o al Senado por mayoría absoluta, pero también al pueblo con una propuesta avalada por medio millón de firmas, propuesta que sería tramitada por el Tribunal Constitucional si la encuentra admisible conforme al ordenamiento legal, y convocado finalmente por el Rey. Como medida de prudencia, podrían excluirse las cuestiones tributarias y presupuestarias, asi como las relaciones internacionales. No me parece prudente, en cambio, dar a las Comunidades Autónomas capacidad referendaria, dada nuestra peculiar situación nacionalista y su previsible agitación en manos demagógicas.

c) El referéndum de reforma constitucional y de iniciativa popular.

El Título X, que regula la reforma constitucional, comienza apoyándose en los apartados 1 y 2 del art. 87 para descartar también, de modo implícito, todo 
tipo de iniciativa popular, reservándola exclusivamente a los parlamentarios, esto es, afianzando todavía más la partidocracia. Y ello no sólo en la reforma extraordinaria (cuando se trata de una reforma a la totalidad, o cuando, aun siendo parcial, afecte al Título Preliminar, al capítulo segundo de la sección primera del Título I o al Título II), dado que en tales asuntos un cierto blindaje resulta casi obligado. No obstante, en los términos actuales, las condiciones de dicho referéndum lo convierten en disuasorio, además de inútilmente teatral. Pero resulta incomprensible extender la negativa a la iniciativa popular de reforma constitucional, aunque sea en términos restrictivos, al modo de la iniciativa legislativa popular, respecto de la reforma ordinaria que afecta al resto. Tanta desconfianza en la ciudadanía no puede deberse más que al objetivo antes mencionado.

\section{d) La iniciativa legislativa popular maniatada.}

Tras haber dejado sentado en el primer apartado del art. 87. que «la iniciativa legislativa corresponde al Gobierno, al Congreso y al Senado»; después de haber reconocido en el segundo a las asambleas de las Comunidades Autónoma capacidad para presentar un proyecto de ley (Gobierno) o una proposición de ley (Congreso), en el tercer apartado abre una tímida puerta a la «iniciativa popular», aunque bajo condiciones férreas como el aval de «no menos de 500.000 firmas acreditadas» y eliminando de su ámbito de actuación las materias «de ley orgánica, tributarias o de carácter internacional», advirtiendo que una ley orgánica regulará «las formas de ejercicio y requisitos» de dicha iniciativa. Y ciertamente lo hizo la ley orgánica 3/1984, art. 5.2., donde establece seis supuestos de inadmisión.

¿Por qué tantas cautelas si, en definitiva, la iniciativa legislativa popular había de pasar por el parlamento? Está clara la voluntad de no dejar más que un resquicio para cuestiones secundarias. Pero es que, además, la Mesa del Congreso debe autorizar previamente la iniciativa si la considera admisible. Además, en caso positivo la comisión promotora de la iniciativa dispone de sólo seis meses para allegar el medio millón de firmas acreditadas. ¿A qué vienen tantas prisas cuando después no se fija plazo alguno para su tramitación parlamentaria? En efecto, la iniciativa popular queda pendiente de que la Mesa del Congreso le habilite un tiempo; mientras tanto, simplemente queda aparcada. Y, por supuesto, la comisión promotora no tiene audiencia alguna en el parlamento para explicar y defender su propuesta, a diferencia de las propuestas de las Comunidades Autónomas, en cuyo caso se permite delegar a tres miembros de la Asamblea. Quizá porque éstos son también parlamentarios, aunque sean de segunda. Pero la participación ciudadana se la mantiene a raya, incluso cuando parece dársele algún juego. ¿Por qué no adoptó la versión italiana del referéndum y de la ini- 
ciativa legislativa, dado que fue el referente general del modelo partidocrático? Por la profunda desconfianza, si no ya menosprecio, de la ciudadanía.

\section{e) La ley electoral o el trágalas definitivo.}

En este caso, ha sido ya la ley Orgánica 5/1985 del Régimen Electoral General la responsable de cerrar el margen que dejaba la Constitución (art. 68), que propiamente sólo optaba por el criterio de representación proporcional. Como es bien conocido, existen dos sistemas electorales: el mayoritario (sólo es elegido el candidato que, en lista abierta, obtiene más votos en la circunscripción) y el proporcional (sobradamente conocido). Pero la citada ley Orgánica puso dos muletas a la proporcionalidad pura: marcó un mínimo del 3\% de los votos y adoptó la fórmula D'Hont, que favorece a los grandes partidos sobre los pequeños.

Pero nada impediría un sistema mixto, como el que funciona en Alemania: cada elector tiene dos votos, el primero para elegir un candidato por el sistema mayoritario (la mitad de la cámara en otras tantas pequeñas circunscripciones), y el segundo, a un partido por el sistema proporcional (aunque la circunscripción no es la provincia, sino los 16 Estados Federados). Es cierto que se incluye una restricción que hace que el voto de mayor peso y, en definitiva, el decisivo sea el segundo, ya que su distribución proporcional incide sobre el número de escaños electorales mayoritarios finalmente conseguidos. Pero no es casual que la mitad elegida por el sistema mayoritario incluya a los diputados más valiosos y reconocidos, que son los que cada partido presenta en sus listas abiertas.

Es curioso que para la elección de los senadores se haya optado en España, en cambio, por un sistema básicamente mayoritario, con algunos aditamentos partidistas (senadores elegidos por los parlamentos de las Comunidades Autónomas, de acuerdo con su población y su reparto entre partidos). Para el Congreso, en cambio, se optó por un sistema embarullado del que resultan beneficiados los dos grandes partidos, los partidos nacionalistas y las provincias con menor población, mientras se dificulta extraordinariamente la consolidación de nuevos partidos y se quiebra, pues, gravemente la igualdad y la libertad política de los ciudadanos.

Pero la joya de la partidocracia es el cierre y bloqueo de las listas. Se trata de un ataque frontal a la libertad ciudadana y pienso con R. Soriano y otros que es, además, inconstitucional, ya que impide la elección libre tutelada en varios artículos de la Constitución (el 23.1 dice «libremente elegidos»; el 68.1 establece un «sufragio universal, libre, igual, directo y secreto»). Es imposible justificar el voto libre y, sobre todo, DIRECTO en las listas cerradas y bloqueadas con que ha de toparse el votante. ¿Cuáles son la razones de tal atropello? La omnipresente partidocracia. ¿A qué fines sirve? A la dominación absoluta 
de la oligarquía de cada partido (no es posible cambiar ni el orden de la lista; menos todavía, tachar algún nombre particularmente ofensivo). En efecto, el ciudadano sólo puede ratificar la lista previamente confeccionada por la cúpula de los partidos, en cuya confección ajusta las cuentas pendientes y reparte favores. Pero es que, además, el bloqueo de las listas sólo se hace en España y Portugal (Colomer, 1995, 204).

¿Por qué no presenta cada partido su lista abierta y deja a cada votante la tarea personalísima de confeccionar su propia lista, incluso con candidatos de diversos partidos? Las dificultades de recuento que se esgrimen resultan ridículas. Otra solución podría ser adoptar el doble voto alemán, como alguna vez se ha llegado a barajar; sería una solución a medias, pero conduciría a que los burócratas del partido tuvieran que aflojar sensiblemente su control sobre la mitad del Congreso y abriría el camino a la reforma definitiva por la misma presión ciudadana.

f) El Tribunal de Cuentas y el Defensor del Pueblo, dos instituciones menguadas.

El Tribunal de Cuentas, según el art. 136 de la Constitución, es «el supremo órgano fiscalizador de las cuentas y de la gestión económica de Estado, así como del sector público». Pero en lugar de plantearlo como un ente estatal autónomo y con capacidad sancionadora, se le hace «depender directamente» del Parlamento, tanto en el nombramiento de sus miembros como en sus tareas: «ejercerá sus funciones por delegación». Su actuación está regulada por la Ley Orgánica 2/1982. Por lo que, a la postre, el cometido del Tribunal es más de tipo informativo que de censura: todo lo que se le pide es que elabore un informe anual de las cuentas del Estado y del sector público (que incluye, claro está, las cuentas de los partidos políticos) subrayando las infracciones cometidas y las responsabilidades pertinentes.

Su estatuto es asimilado al de los jueces, excepto en la capacidad de juzgar las cuentas. Su informe pasa a los partidos políticos y se diluye en una serie de debates y acusaciones interpartidistas finalmente estériles, salvo rara execepción. Los abusos en la financiación suelen terminar en una subida de la financiación pública de los partidos, como si ésta fuera la responsable. Se hace necesario, en cambio, transformar el Tribunal de Cuentas en una Comisión de Control de los Partidos, formada por expertos independientes (al menos, al modo del Consejo de Estado), pero con poderes ejecutivos y a cubierto de toda intromisión partidista, como se viene reclamando también en otros países.

El estatuto del Defensor del Pueblo, regulado en el art. 54, sigue un planteamiento similar. En este caso, en cambio, resulta lógico que sea nombrado por las Cortes Generales como «alto comisionado de las mismas» para «la defensa 
de los derechos y deberes fundamentales», facultándole para «supervisar la actividad de la Administración» y elevando informes al Parlamento. También aquí, por tanto, su función esencial es la informativa, porque es el Parlamento quien decide. Todo podía ser correcto si el Partamento no estuviera inmerso en la partidocracia y el partidismo. Es cierto que la Ley Orgánica 3/81 amplía las funciones del Defensor a la intermediación social, como una alternativa a la vía judicial, en determinados casos. Pero lo real es que tampoco tiene fuerza jurídica vinculante. Puede, en principio, nombrar a uno o más Adjuntos, pero sus medios son escasos. Por otra parte, tampoco son claras las relaciones jurídicas del Defensor y los gestores públicos, lo que genera confusiones y, no raramente, indefensiones. En definitiva, su única competencia clara es la de elevar un informe anual, así como los infomes especiales que considere, al Parlamento. Lo que éste decida, dentro de su habitual corporatismo, ya queda fuera de su ámbito. Es obvio que lo que precisa es capacidad procesal activa para interponer directamente recursos ante la jurisdicción pertinente, de oficio o a instancia de parte. Sucede además que este cargo viene funcionando de forma muy politizada, según el consabido sistema de cupo partidista. Y no es cuestión de prestigio y buena voluntad, sino de dotarle de los medios adecuados. Claro que eso es lo que no hará nunca la partidocracia.

g) Listas electorales paritarias: otra vuelta de tuerca con fines clientelares.

Tras lo dicho sobre la manifiesta inconstitucionalidad del bloqueo de las listas cerradas, poco más habría que decir de la reciente ley que exige la paridad (60/40, al menos) de las listas electorales, dado que la cremallera paritaria refuerza, si cabe, el bloqueo de las listas, impidiendo todavía más la libertad de elección del ciudadano entre los candidatos. Ello hace más imposible el voto «libre» y «directo» que la Constitución avala a los electores. Y sentado esto, poco más hay que añadir.

Pero resulta bastante obvio además que, como ocurrió en Francia, se trata primordialmente de una operación de clientelismo político, aunque bastante simplista: el partido que se gane el favor del voto femenino tiene garantizada la victoria electoral para siempre. Aunque quizá resulte más exacto decir que la paridad electoral es el producto del cruce entre el clientelismo político de los partidos (incluso el Partido Popular, no paritario, no votó en contra, sino que se abstuvo) y la ambición personal de muchas feministas de izquierdas, que no pueden esperar a que la misma evolución político-social resuelva espontáneamente el problema, sin artificialismos y sin forzar la voluntad de los electores de cualquier sexo. Si hoy las mujeres son ya más de un tercio, todo indica (no hay más que ver lo que sucede en los partidos no paritarios) que en la próxima 
generación alcanzarán la mitad y la sobrepasarán rápidamente después (Rubio Carracedo 2005).

Otra posible inconstitucionalidad añadida es obligar a los partidos no paritarios a ser paritarios: ¿dónde queda la libertad de los partidos? Una cuestión distinta es que los presidentes tengan libertad en el nombramientos de los ministros o consejeros (género epiceno, por favor) para atenerse o no a la paridad, aunque ya conocemos a varios campeones voluntarios. Incluso resulta obvio que hoy ser mujer es una ventaja para ciertos cargos o premios. Se echa en falta, en cambio, el mismo celo de políticos y feministas en erradicar la lacra infame de la discriminación laboral. Tal vez toda esta operación paritaria termine desprestigiando, injustamente, a la mujer en su conjunto y pueda suponer un retroceso real en sus legítimas conquistas sociales y políticas.

\section{h) La educación para la ciudadanía.}

Considero muy probable que el art. 48 de la Constitución exige, al menos, la disposición de una materia de carácter obligatorio para propiciar una educación cívico-democrática de los ciudadanos, ya que responsabiliza a los poderes públicos de «promover las condiciones para la participación libre y eficaz de la juventud en el desarrollo político, social, económico y cultural». Tanto más cuanto que ya el 27.2 asevera que «la educación tendrá por objeto el pleno desarrollo de la personalidad humana en el respeto a los principios democráticos de convivencia y a los derechos y deberes fundamentales». Los sucesivos gobiernos se han limitado al inoperante Consejo de la Juventud. El gobierno actual pareció dispuesto en principio a cumplimentar el mandato constitucional, es decir, la creación -solicitada desde hace tanto tiempo y exigida por una Directiva Europea- de una materia en la que se educara (es decir, se instruyera y motivase) a los futuros ciudadanos en los valores cívico-democráticos. Pero finalmente el Gobierno, por un puñado de votos de socialistas católicos, no ha sabido resistir las presiones y ha optado por hacer obligatoria una asignatura en Primaria y Secundaria que no cumple con las exigencias mínimas, porque una hora semanal, aunque sea en Primaria y dos cursos de Secundaria, es proponer una «maría»; esto es, darle, de cara a los alumnos, un estatuto de materia de tercera categoría. Y resulta ya deprimente que sólo dos de las autonomías gobernadas por el PSOE (Castilla-La Mancha y Extremadura) han añadido una hora más de su libre disposición en Secundaria. Con el agravante colateral de que la Etica de $4^{\circ}$ de Secundaria ha sido rebajada a una hora semanal en algunas Autonomías.

Lo pertinente hubiera sido una materia obligatoria, independiente de la Etica, en $3^{\circ}$ o $4^{\circ}$ de Secundaria, con 3 horas semanales e impartida por un profesorado autónomo y específicamente preparado. Y en el temario, además 
de las cuestiones ya apuntadas, deberían figurar materias formativas como la igualdad de oportunidades, la compleja problemática de las drogas, cuestiones jurídicas elementales, educación sexual, educación vial, etc. ¿Por qué aquella chapuza impresentable? No se sostiene que algo es muy importante, pero puede adquirirse en una hora semanal, difusa en el tiempo, además, y sin un profesorado específico. Por otra parte, en los temarios oficiales se observa mucho más empeño en las cuestiones éticas que en las propiamente político-democráticas. Es cierto que de ello no se deduce ningún sesgo doctrinario, pues la libertad de cátedra se respeta en todo momento. Pero tampoco se fomenta la formación de una ciudadanía crítica y vigilante con el poder. Se hace necesario, pues, replantearla como la materia más importante que es de todo el currículo.

\section{i) En un estado aconfesional, la religión ha de pasar al ámbito privado.}

Como una cuestión derivada de la precedente, resulta bastante obvio que en un estado aconfesional las creencias religiosas han de pasar al ámbito privado. La Constitución refleja también aquí su sesgo transicional y ambiguo. Así el art. 16.1 garantiza la «libertad ideológica, religiosa y de culto», así como sus manifestaciones compatibles con el orden público. El 16.2 refuerza claramente el carácter privado de la «ideología, religión o creencias» al vetar que «nadie pueda ser obligado a declarar» sobre las mismas. Pero el 16.3 abre un amplio resquicio al ámbito público cuando, tras aseverar que «ninguna confesión tendrá carácter estatal», recomienda que «los poderes públicos tengan en cuenta las creencias religiosas» de los españoles y mantengan «relaciones de cooperación con la Iglesia Católica y las demás confesiones».

Pronto se van a cumplir treinta años de la Constitución, en los que la sociedad española se ha secularizado considerablemente, hasta trocar el anticlericalismo en indiferencia. Asi como del Concordato con la Santa Sede (1979), en el que la «colaboración» genérica constitucional se hizo colaboración activa y financiada. ¿A qué espera un gobierno de centro-izquierda para denunciar dicho Concordato abusivo, sólo inteligible por razones transicionales? Una vez más, la obsesión por obtener votos -o por no perderlos- es la actitud dominante de nuestra clase política. Es la cuestión suprema -la adquisición y el mantenimiento del poder- a la que todo se subordina. Tanto que ha tenido que intervenir la Unión Europea para vetar la exención fiscal de la Iglesia Católica y las aportaciones directas del estado, aunque se haya compensado subiendo al 0'7\% la contribución voluntaria en el IRPF, sin cautela temporal alguna además (I. Sotelo 2007), con la renuncia expresa al ideal de la autofinanciación en el futuro, con lo que todos los ciudadanos, agnósticos o de cualquier otra creencia, contribuyen a la financiación de la Iglesia Católica con 3,5 € (J. G. Bedoya 2008). 
Es posible que la obligada colaboración «con las demás confesiones», exigida por el 16.3, pueda traer alguna luz al variopinto vivero de las clases de religión en la escuela pública (que no en la concertada). ¿Qué hace la clase de religión-catequesis en la enseñanza pública de un estado aconfesional y en una sociedad crecientemente laica? Debería sustituirse de inmediato por una Historia de las Religiones, impartida por historiadores y filósofos imparciales, dada la indudable relevancia histórica y cultural del hecho religioso y sus manifestaciones artísticas. La clase confesional, esto es, la catequesis, tiene su lugar propio en las iglesias, mezquitas, sinagogas, etc., que para eso están. Y puesto que las creencias religiosas son respetables, pero privadas, nadie impide a los padres creyentes el financiarlas, en lugar de exigir que se las financien los demás. Como hacemos los demás con nuestras creencias privadas.

\section{REFERENCIAS BIBLIOGRÁFICAS}

BARBER, B., 1984: Strong Democracy. Participatory Politics for a New Age. University of California Press. Democracia fuerte. Córdoba, Almuzara, 2004.

BEDOYA., J.G. 2008: «Las concesiones de Zapatero». El País, 3.1.2008.

CASTILLO, P. del, 1978: «La campaña del referédum constitucional». Revista de Estudios Políticos, 6.

COLOMER, J. M., 1995: «España y Portugal: regímenes de liderazgo de partido», en J.M. Colomer, (ed.), La política en Europa, Barcelona, Ariel, 199-243.

CONSTANT, B., 1818: «De la liberté des anciens comparée â celle des modernes», en Cours de politique constitutionnelle.

DAHL, R., 1982: Dilemmas of a Pluralist Democracy: Autonomy versus Control. New Haven, Yale University Press.

ESTEBAN, J. de, y LÓPEZ GUERRA, L., 1982: El régimen constitucional español. 2 vols. Barcelona, Labor Universitaria.

HELD, D., $1996\left(2^{\mathrm{a}}\right)$ : Models of Democracy. Cambridge, Polity Press. Existe v. esp.

MACPHERSON, C.B.: 1970, La teoría política del individualismo posesivo. Barcelona, Fontanella; Madrid, Trotta.

MANIN, B., 1998: Los principios del gobierno representativo. Madrid, Alianza.

PETTIT, P., 1999: Republicanismo. Barcelona, Paidós.

RUBIO CARRACEDO, J. 2000: «Por un modelo democrático liberal-republicano», en Retos pendientes en ética y política. Ed. por J. Rubio Carracedo, JM. Rosales y M. Toscano, Málaga, Contrastes; 2002, Madrid, Trotta; 2005, Ciudadanos sin democracia. Granada, Comares.

SORIANO, R. y RASILLA, L., $2002\left(2^{\mathrm{a}}\right)$ : Democracia vergonzante y ciudadanos de perfil. Granada, Comares.

SOTELO, I., 2007: «La "cuestión religiosa"». El País, 2.9.2007, 13-14.

TORRES DEL MORAL, A., 1985-6: Principios de Derecho Constitucional español. 2 vols. Madrid, Atomo. 
Jose Rubio-CArracedo es catedrático de Etica y Filosofía Política en la Universidad de Malaga.

Publicaciones recientes:

Ciudadanos sin democracia. Granada, Comares, 2005; y Teoría crítica de la ciudadanía democrática. Madrid, Trotta, 2007.

Líneas de investigación:

Su línea de investigación preferente ha sido «La democracia de los ciudadanos», así como «La ciudadanía democrática».

Dirección postal:

Departamento de Filosofía. Facultad de Filosofía y Letras. Campus de Teatinos. 29071 - Málaga (España).

Dirección electrónica: jrcarracedo@uma.es 